\title{
A mediational model linking perceptions of security, alexithymia and behavior problems of sexually abused children
}

\author{
Cyndi Boisjoli $^{\mathrm{a}}{ }^{* *}$, Martine Hébert ${ }^{\mathrm{b}}$, Amélie Gauthier-Duchesne ${ }^{\mathrm{b}}$, Pier-Olivier Caron ${ }^{\mathrm{c}}$ \\ a Département de psychologie, Université du Québec à Montréal, C.P. 8888, succursale Centre-Ville, Montréal, QC, H3C 3P8, Canada \\ ${ }^{\mathrm{b}}$ Département de sexologie, Université du Québec à Montréal, C.P. 8888, succursale Centre-Ville, Montréal, QC, H3C 3P8, Canada \\ ${ }^{\mathrm{c}}$ Télé-Université, 5800, Rue Saint-Denis, Bureau 1105, Montréal, QC, H2S 3L5, Canada
}

\section{A R T I C L E I N F O}

\section{Keywords:}

Child sexual abuse

Alexithymia

Perception of security toward mother

Perception of security toward father

Behavior problems

\begin{abstract}
A B S T R A C T
Background: Perceptions of security toward parents are related with internalized and externalized problems among victims of child sexual abuse (CSA). Alexithymia, which is difficulty in identifying and expressing feelings, is associated with the quality of parent-child relationships (Oskis et al., 2013) and behavior problems in children (Di Trani et al., 2013).

Objective: The current study tested the mediational role of alexithymia in the relationship between perceptions of security toward parents and behavior problems among CSA victims.

Participants and method: Using a short-term multi-informant prospective design, 263 victims of CSA aged 6-12 years completed the Kerns Security Scale (Kerns, Klepac, \& Cole, 1996), which evaluates perceived attachment security to mothers and fathers. Parents completed the Child Behavior Checklist (Achenbach \& Rescorla, 2001) at Time 1 to provide baseline scores of behavior problems and again four months later. At Time 2, parents also assessed the children's alexithymia using the Children's Alexithymia Measure (Way et al., 2010).

Results: Perceptions of security were both associated with alexithymia, as well as with internalizing and externalizing problems $(p<.05)$. A mediational model showed that perception of security toward fathers outweighed the mother-child relationship in predicting children's alexithymia. Path analysis revealed that the father-child relationship predicted decreased behavioral problems at Time 2 through a lower level of alexithymia. The model explained $46.9 \%$ of internalizing problems and $56.1 \%$ of externalizing problems $(p<.05)$.

Conclusions: The findings support the relevance of alexithymia as an intervention target for CSA victims and underscore the importance of the father-child relationship.
\end{abstract}

\section{Introduction}

Despite the vast implementation of prevention programs over the past decades, child sexual abuse (CSA) remains a significant global issue. According to a recent meta-analysis, $15 \%$ of girls and $8 \%$ of boys report experiencing sexual abuse prior to the age of 18 (Barth, Bermetz, Heim, Trelle, \& Tonia, 2013). It is well known that CSA is associated with deleterious effects in victims, particularly in cases of early onset (Marriott, Hamilton-Giachritsis, \& Harrop, 2014). Compared to their non-abused peers, sexually abused children display more emotional difficulties as well as internalizing (e.g., depression, anxiety, somatization) and externalizing (e.g., aggressiveness, rule-breaking behaviors) problems (Vachon, Krueger, Rogosch, \& Cicchetti, 2015). There is a need to shed light on the

\footnotetext{
* Corresponding author.

E-mail addresses: boisjoli.cyndi@courrier.uqam.ca (C. Boisjoli), hebert.m@uqam.ca (M. Hébert), gauthier-duchesne.amelie@courrier.uqam.ca (A. Gauthier-Duchesne), pier-olivier.caron@teluq.ca (P.-O. Caron).
} 
mediators involved in the association between CSA and negative outcomes among school-aged victims of CSA (Hébert, 2011a). Identifying and explaining the mechanism or process that underlies the relationship between CSA and behavior problems is likely to offer cues for intervention.

Understanding the heterogeneous profiles of these victims requires the consideration of different variables that may influence outcomes, as suggested by the theoretical perspective of the transactional model (Sawyer \& Hansen, 2014; Spaccarelli, 1994). This model underscores the relevance of considering a series of transactions between the victim and his environment to better understand the complexity of the child's adaptation. As described by Spaccarelli (1994), the adaptive trajectory of young CSA victims is not static but rather is influenced by a series of interrelated factors. The current study follows this theoretical postulate by considering both personal (e.g., gender, age, alexithymia) and environmental factors (e.g., perception of security, psychosocial intervention). Several studies have focused on abuse-related characteristics (e.g., severity of the CSA, identity of the perpetrator) to explain the diversity of profiles in victims of CSA; however, these variables are not amenable to change. The exploration of personal and environmental factors is more likely to offer relevant insights regarding important targets for intervention (Yancey \& Hansen, 2010).

Numerous studies have highlighted the essential role of familial factors such as parental support and the quality of the parentchild relationship, in the developmental trajectories of CSA victims (Bolen \& Gergely, 2015). However, these studies mainly focus on the mother-child relationship and use retrospective designs among adult survivors of CSA. The current study overcomes these limitations by investigating the perception of security among school-aged victims of CSA, referring to the self-reported quality of the child's relationship with both maternal and paternal caregivers. This study also examines an innovative, yet understudied, personal factor that may contribute to explaining the heterogeneity of profiles found in sexually abused children: alexithymia. Alexithymia is defined as the difficulty in identifying and expressing feelings and appears to be associated with both the quality of parent-child relationships and negative outcomes (Taylor \& Bagby, 2013). Studies reveal that alexithymia may be especially prevalent among CSA survivors (Hébert, Boisjoli, Blais, \& Oussaïd, 2018; Thomas, DiLillo, Walsh, \& Polusny, 2011). Alexithymia may represent a mechanism by which CSA is associated with adverse outcomes.

\subsection{Importance of parent-child relationships for CSA victims}

Numerous studies have underlined the crucial role of the parent-child relationship in helping CSA victims overcome the aftermaths of the trauma. In fact, studies relying on retrospective designs report that familial factors may be more salient predictors of long-term effects of CSA than abuse-related characteristics (Bhandari, Winter, Messer, \& Metcalfe, 2011). In the short term, the significant influence of the quality of parent-child relationships on CSA victims' symptomatology has also been identified (Bolen \& Lamb, 2007). Among preschoolers, attachment is often assessed with observational measures such as the strange situation procedure (Ainsworth, Blehar, Waters, \& Wall, 1978). For school-aged children, self-reported measures of parent-child relationships evaluating perceptions of security appear particularly relevant (Brumariu, Madigan, Giuseppone, Movahed Abtahi, \& Kerns, 2018). To date, there is a paucity of scientific literature on parent-child relationships during middle childhood in comparison to other developmental periods, and the available studies focus primarily on mothers (Brumariu \& Kerns, 2010; Kerns \& Brumariu, 2016). The mother-child relationship has been acknowledged as a significant predictor of a wide array of internalizing symptoms, such as anxiety and depression (Brumariu \& Kerns, 2010; Venta, Mellick, Schatte, \& Sharp, 2014). In addition, the mother-child relationship has been found to impact children's externalizing symptomatology (Kim \& Cicchetti, 2004; Madigan, Brumariu, Villani, Atkinson, \& Lyons-Ruth, 2016). However, much of the research to date has examined the quality of parent-child relationships without distinguishing the specific influence of the relationship with the mother and the father (Madigan et al., 2016). Because a minority of CSA is perpetrated by the biological father, the paternal caregiver could act as a significant supportive figure in the context of CSA disclosure (Sedlak et al., 2010). Therefore, both caregivers may play essential yet distinctive roles in supporting the child's recovery.

Although a large body of studies has focused on mother-child relationships, there is empirical evidence indicating that fathers have a distinct, albeit complementary, role in the child's development (Paquette, 2004). While mothers focus on proximity and caregiving, fathers enhance exploration by spending more time playing and doing activities that are physical and emotionally challenging for children (Dumont \& Paquette, 2008). Unfortunately, studies on CSA victims that explore paternal influence remain scarce and generally rely on retrospective designs using adult samples (Bolen \& Gergely, 2015; Guelzow, Cornett, \& Dougherty, 2003).

However, recent empirical findings have demonstrated that both mothers and fathers play a significant role in victims' psychological adjustment. Perceived attachment security to the mother and father has been found to be associated with outcomes including lower post-traumatic stress symptoms among school-aged victims of CSA (Hébert, Daspe, \& Cyr, 2017). Parent-Boursier and Hébert (2010) revealed that the perception of security toward both mothers and fathers contributed significantly to the prediction of self-reports on self-esteem and internalizing behavior problems in school-aged victims of CSA. In a subsequent study (2015), the authors found that only the perception of security toward the father significantly to the prediction of parental reports of children's behavior problems, even when controlling for age, gender and maternal distress. These studies support the importance of distinguishing the child's relationship with the mother and the father. However, little is known about the factors that account for the association between perceptions of security and behavior problems among CSA victims.

\subsection{Parent-child relationship and emotional competencies}

The parent-child relationship has a major influence on the child's emotional competencies, which in turn appear to have a significant impact on the trajectories of young victims of CSA (Langevin, Cossette, \& Hébert, 2016). In the earliest years of life, 
parents are external agents in charge of identifying, interpreting and responding to a child's physical and emotional needs (Holodynski \& Friedlmeier, 2006; Thompson, 2013). Their availability and sensitivity combined with the child's reactivity constitute an interpersonal and organized form of regulation (Holodynski \& Friedlmeier, 2006). A child progressively internalizes this organization during childhood and becomes more autonomous by developing his own capacity to identify and manage emotional content (Thompson, 2013). According to the attachment theory framework, individual differences in emotional abilities can also result from secure or insecure relationships with parents (Bowlby, 1977, 1982; Cassidy, 1994). Based on the developmental perspective, a longitudinal study by Lemche, Klann-Delius, Koch, and Joraschky (2004) showed that securely attached children presented an accelerated development of mentalizing language, while children with insecure attachment presented a delay in the acquisition of this skill. Indeed, secure relationships stem from parents who are sensitive and receptive to their child's feelings, whether these feelings are positive or negative. These attitudes support the child's tendency to develop emotional awareness and to share his feelings. On the other hand, an insecure relationship might adversely affect these abilities by nurturing an environment that discourages the child's emotional expressiveness (1982, Bowlby, 1977; Cassidy, 1994). Such difficulties in the parent-child relationship may predispose these children to develop the difficulty referred to as alexithymia.

\subsection{Alexithymia}

The term alexithymia primarily refers to difficulty in identifying and expressing emotions (Nemiah \& Sifneos, 1970; Sifneos, 1973). The prevalence of alexithymia among adolescents in the general population varies between $7.3 \%$ and $29.9 \%$ (Honkalampi et al., 2009; Joukamaa et al., 2007; Säkkinen, Kaltiala-Heino, Ranta, Haataja, \& Joukamaa, 2007; Zimmermann, Quartier, Bernard, Salamin, \& Maggiori, 2007). To our knowledge, no data regarding the prevalence of alexithymia are currently available for children.

Empirical reports among adults of the general population have shown significant associations between alexithymia and a host of difficulties, including internalizing symptoms such as somatization (Mattila et al., 2008), psychological distress (Orejuela-Dávila, Cann, \& Tedeschi, 2017), post-traumatic disorder (Frewen, Dozois, Neufeld, \& Lanius, 2008), depression and anxiety (Hamaideh, 2017). There is also a growing body of research that supports the association between alexithymia and externalizing problems, such as impulsivity (Gaher, Arens, \& Shishido, 2015) and aggression (Velotti et al., 2016). The few studies conducted with children have obtained similar results. Alexithymia significantly predicts symptoms such as internalizing and externalizing problems, which often co-occur (Di Trani et al., 2013; Rieffe \& De Rooij, 2012). Given that childhood is a critical period for emotional development (Lemelin \& Tarabulsy, 2012), research on alexithymia in this age group appears to be particularly relevant to prevent the emergence and crystallization of symptoms. Considering that emotional capacities are still evolving in childhood and adolescence, an age-related decrease in alexithymia is generally observed (Parker, Eastabrook, Keefer, \& Wood, 2010). Inconsistent results have been found regarding gender differences. Some authors report that boys are more likely to be alexithymic (Levant, Hall, Williams, \& Hasan, 2009), while others show the opposite (Craparo, Gori, Petruccelli, Cannella, \& Simonelli, 2014) or no difference between boys and girls (Schimmenti et al., 2017).

Past studies have shown that adult and adolescent victims of CSA generally exhibit higher levels of alexithymia when compared to non-victimized adults (Thomas et al., 2011, Houck, Nugent, Lescano, Peters, \& Brown, 2010). In addition, a recent study revealed that alexithymia mediated the relationship between CSA and psychological distress among adolescents (Hébert et al., 2018). In fact, early childhood trauma, especially maltreatment, constitutes a well-known factor for the development of alexithymia (Taylor \& Bagby, 2013). Alexithymia appears to be a strategy used by victims to cope with negative affect generated by trauma (Lecours, Philippe, Boucher, Ahoundova, \& Allard-Chapais, 2016). In other words, traumatic events may interfere with children and adults' emotional abilities (Kim \& Cicchetti, 2010; Krystal, 1988). Despite its relevance, alexithymia remains understudied among CSA victims, especially in children. In addition, a common bias in the literature is the use of a self-reported measure of alexithymia, which is questionable given that alexithymic individuals may fail to accurately report their own deficit in affect awareness (Taylor \& Bagby, 2013).

Several studies among general and clinical adult populations have supported the critical influence of parent-child relationships in alexithymia (Taylor \& Bagby, 2013). These findings also appear in the rare studies focusing on the influence of secure or insecure relationships on alexithymia among youth samples (Besharat \& Khajavi, 2013; Deborde et al., 2012; Oskis et al., 2013). None of these studies has specifically explored parent-child relationships and alexithymia in childhood.

Relatedly, prior studies have suggested that alexithymia may account for the association between the quality of parent-child relationships and behavioral problems among CSA victims. A frequent bias is to omit to differentiate the child's relationship with the mother and the father, who may have different contributions to alexithymia (Gil, Scheidt, Hoeger, \& Nickel, 2008). A meta-analysis of parental bonding and alexithymia showed consistent findings across studies with student samples: maternal factors appeared to have a clear impact on alexithymia, while the father had a smaller, but significant, influence (Thorberg, Young, Sullivan, \& Lyvers, 2011). Nonetheless, the results of studies with clinical samples showed that fathers had a stronger influence on alexithymia. In sum, this meta-analysis highlighted the need for further research to understand the specific contribution of mothers and fathers in alexithymia, especially for clinical samples of children.

\subsection{Aims}

The purpose of the current study was to test alexithymia as a mediator of the link between the child's perceived attachment security to the mother and father and outcomes following CSA, as shown in Fig. 1. More specifically, this study aimed to examine alexithymia as a mediator of the relationship between maternal/paternal perceptions of security assessed at Time 1 and internalizing 


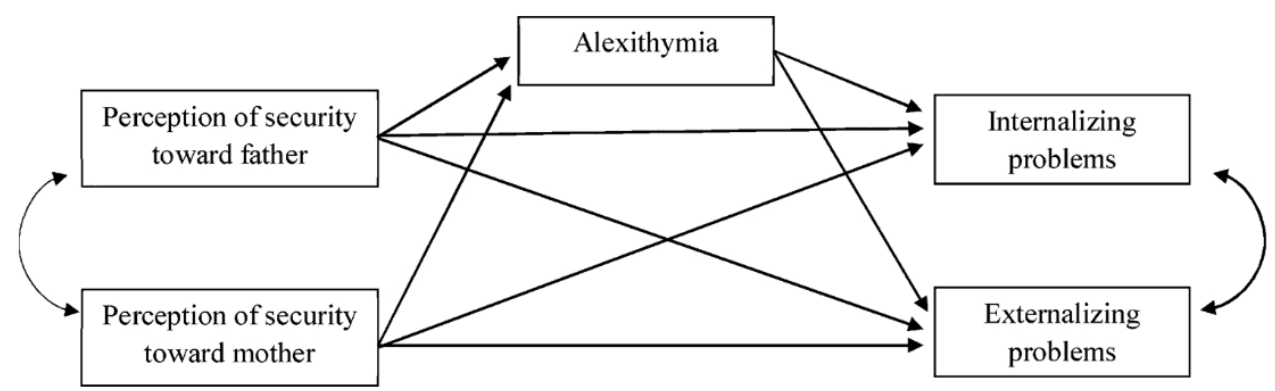

Fig. 1. Mediational Model Tested.

Notes. Control variables are included, but not illustrated in the model.

and externalizing behavior problems assessed 4 months later among school-aged victims of CSA.

\section{Method}

\subsection{Participants}

At baseline (T1), the sample consisted of 263 sexually abused children (62.7\% of girls and $37.3 \%$ of boys) aged $6-12(M=8.80$, $S D=1.82$ ) and their parental figure. Respondents were mostly the biological mother (72.4\%), followed by the biological father (11.3\%), a foster parent (8.2\%), another family member (5.1\%) or step-parent (3.1\%). Almost one-third of the children lived in intact families (27.9\%), while the others lived in single-parent families (26.0\%), recomposed families (30.6\%) or foster families (15.5\%). Regarding parental education, the majority of mothers (59.5\%) and almost half of fathers (49.1\%) had a college or university level of education. The majority of participants were Caucasian (90.5\%) and had an annual family income under $\$ 60000$ (66.0\%).

Families were recruited in four centers offering specialized services for victims of CSA in the province of Quebec, Canada. The current study only included children identifying two significant and non-offending caregivers. An inclusive definition of a significant parental figure was used (biological, legal tutor, or step-parent living with the child part time or full time). At the follow-up assessment four months later (T2), 196 families agreed to participate. A total of $28.3 \%$ of children reported experiencing a single episode of CSA, while the majority reported multiple episodes (35.9\%) or episodes lasting more than 6 months (35.9\%). Most of the children $(57.8 \%)$ reported very severe CSA, defined by penetration or attempted penetration (oral, vaginal, or anal). Approximately one-third (32.8\%) of the sample experienced severe CSA characterized by physical contact under clothing, and $9.4 \%$ reported less severe experiences with physical contact over clothing, exhibitionism or incitement to sexual activity. More than two-thirds (72.5\%) of the sample experienced intrafamilial CSA, which is defined as sexual abuse perpetrated by an immediate (e.g., father, brother) or extended family member (eg., uncle, grandparent).

\subsection{Procedure}

Families were recruited in treatment centers for sexually abused children. During the first visit, parents who agreed to participate signed the consent form and completed the questionnaire on their own or with assistance if needed. Children completed the questionnaire in another room with the help of a trained research assistant. At the follow-up assessment approximately four months later $(M=4.78, S D=2.72)$, families were met at home by a trained research assistant or at the intervention center. This research was approved by the human research review committee of the Centre hospitalier universitaire Sainte-Justine and the internal review board of the Université du Québec à Montréal.

\subsection{Measures}

\subsubsection{Sociodemographic characteristics}

Parental figures completed a questionnaire to gather information such as the child's age, gender, family structure, family income, ethnicity and parental education level.

\subsubsection{Abuse-related characteristics}

CSA characteristics were collected using an adaptation of the History of Victimization Form (HVF; Parent \& Hébert, 2006) completed by trained research assistants who had access to the child's medical or clinical files. Based on 30 records, this measure showed high inter-rater reliabilities with a median intra-class correlation of 0.86 and a median inter-rater agreement of $92.8 \%$ (Parent \& Hébert, 2006). The HVF provided information on the severity of the CSA (no physical contact, physical contact under clothing and penetration), frequency of the CSA (one episode, less than 6 months or more than 6 months) and relation to the perpetrator (immediate family, extended family, family acquaintance or a stranger). 


\subsubsection{Perception of security}

A French adaptation (Hébert, 2001) of the Security Scale (Kerns, Klepac, \& Cole, 1996) measured the child's perception of security toward the mother and the father. According to Kerns and colleagues, the perception of security refers to 1) the belief that a parental figure is accessible and responsive, 2) the child's reliance on this figure in stressful situations and 3) the ease and interest of the child in communicating with the parental figure. This self-reported measure includes nine items and is completed separately for nonoffending maternal and paternal figures. The children answer on a four-point scale using Harter's format (1982) (e.g., "Some kids think their mom/dad does not listen to them but other kids do think their mom/dad listens to them"). After indicating which type of child represents them best, the children indicate whether it is "really true" or "sort of true" for them. The Security Scale yields a total score between 9 and 36 for each caregiver, which was transformed into a dichotomous score (secure or insecure) following Bacro's procedure (2011) obtained in the French version. Similar to the authors of the Security Scale and Bacro (2011), differential thresholds were used for the mother (2.80) and father (2.70). If possible, the children were invited to answer the questionnaire in relation to their biological mothers $(84.8 \%)$ and fathers $(76.0 \%)$. Otherwise, the children completed questions in relation to a significant parental figure present in their life for at least one year. For maternal figures other than their biological mother, the participants completed the measure in relation to their step-mother (3\%), foster mother (8.4\%) or another member of the family (3.8\%). For paternal figures other than their biological father, the children completed the questionnaire in relation to their step-father (11.0\%), foster father $(8.8 \%)$ or another member of the family $(4.2 \%)$. None of the children had same-sex parental figures. In cases of CSA involving a biological parent $(n=21)$, the children were asked to complete the Security Scale with reference to a substitutive significant parental figure (e.g., step-father). Internal consistency was satisfactory for the mother-child questionnaire ( $\alpha=.75)$ and good for the father-child questionnaire $(\alpha=.85)$.

\subsubsection{Alexithymia}

Parents completed the French version of the Children's Alexithymia Measure (CAM; Way et al., 2010; Hébert, 2011b) designed for children aged 5-17 who have experienced a traumatic event. The CAM contains 14 questions that assess the child's level of alexithymia using a four-point Likert scale $(0=$ almost never to $3=$ almost always). Sample items include "Has trouble finding words or getting words out when talking about his/her own feelings", "Changes the topic of the conversation when asked about his/her feelings" and "Has difficulty saying he/she feels sad even though he/she looks sad". In the current study, the internal consistency was high ( $\alpha=.89)$. According to taxometric studies (Keefer, Taylor, Parker, \& Bagby, 2017; Mattila et al., 2010; Parker, Keefer, Taylor, \& Bagby, 2008), alexithymia appears to be a dimensional construct and not a categorical construct. Thus, the alexithymia level was measured using a continuous score.

\subsubsection{Internalizing and externalizing behavior problems}

The Child Behavior Checklist (CBCL; Achenbach \& Rescorla, 2001) was completed by the parent to evaluate the presence of behavior problems displayed by the child. This widely used measure includes 118 items rated on a three-point Likert scale $(0=$ not true, 1 = somewhat or sometimes true, 2 = very true or often true). Parents completed this measure at T1 and T2 to control for behavior problems at baseline. The total scores of internalizing and externalizing problems were transformed into a T-score based on Achenbach and Rescorla's norms (2001) obtained among normalization samples. Higher scores reflect a higher level of behavior problems. In the present study, the internal consistency was high for both internalizing $(\alpha=.89)$ and externalizing problems $(\alpha=.92)$ scales.

\subsubsection{Parental support}

The Parental Reaction to Abuse Disclosure Scale (PRADS; Everson, Hunter, \& Runyan, 1989; Thériault, Cyr, \& Wright, 1995) was completed by a trained clinician based on semi-structured interviews with the parent and the child separately to evaluate abusespecific support. The PRADS measures four dimensions: belief in a child's disclosure, emotional support offered, steps taken regarding the perpetrator and use of professional services. Interviewers coded the responses and summed the four dimensional scores to obtain a total ranging from -8 (no support) to +8 (highly supportive). Past studies have shown satisfactory inter-rater reliability (0.82) (Thériault, Cyr, \& Wright, 2003), and the internal consistency of the current study was good $(\alpha=.82)$.

\subsection{Data analysis}

First, preliminary analyses (missing data analyses, descriptive analyses and bivariate correlations) were conducted using SPSS 24. The correlational analyses were used to examine the associations between the studied variables. Variables not significantly associated with the other studied variables were not included in the final model to be tested. In addition to the variables presented in the research hypotheses, several control variables were included: gender, age, involvement in psychosocial intervention between T1 and T2 and behavior problems at baseline (see Fig. 1). Considering that the gender and age of the child may have an impact on alexithymia (Parker et al., 2010) and behavior problems (Gauthier-Duchesne, Hébert, \& Daspe, 2017), it was recommended to control for these variables. The presence or absence of psychosocial intervention between $\mathrm{T} 1$ and follow-up was also controlled for in the statistical analyses. Regarding missing data, families who participated in both $\mathrm{T} 1$ and $\mathrm{T} 2$ were compared to families who only participated in T1. No significant differences were observed regarding the perception of security toward mothers and fathers, CSA characteristics, family structure, family income, ethnicity and parental education levels. Chi-square and analyses of variance showed that neither the perception of security nor alexithymia varied significantly $(p>.10)$ across family structures. Moreover, there was no significant difference of paternal perception of security scores of children abused by their biological father and scores of children 
abused by another perpetrator $(p>.10)$. Therefore, data were considered to be missing completely at random.

Second, path analyses were performed using Mplus 6.0 (Muthén \& Muthén, 1998-2007). Perceptions of security toward mothers and fathers were measured at T1, and endogenous variables (alexithymia and behavior problems) were measured at T2. The pathway from attachment to alexithymia is based on theoretical considerations as discussed in the review of Taylor and Bagby (2013). Several studies, such as Lemche et al. (2004) and the meta-analysis of Thorberg, have adopted this conceptualization. The ML estimator of Mplus was used because the Full Information Maximum Likelihood adequately accounts for missing data. Bias-corrected bootstrap confidence intervals of $95 \%$ were conducted. The recommendations for cut-off criteria for fit indexes (Hu \& Bentler, 1999), which are non-significant $\chi^{2}$, RMSEA below 0.08 , CFI over 0.95 and TLI over 0.95 , were followed.

\section{Results}

\subsection{Descriptive results}

Data from T1 on the perception of security toward the maternal figure showed that $90.1 \%$ of the children had a secure score on the KSS, compared to $9.9 \%$ who had an insecure score. A significantly higher proportion of insecure scores was observed regarding the perception of security toward the paternal figure: $21.3 \%$ of the children had an insecure score, while $78.7 \%$ had a secure score. Considering the presence of a ceiling effect, dichotomous scores based on Bacro's cut-off scores (2011) were used for subsequent analyses.

Data from the PRADS revealed that more than three-quarters (83.3\%) of the parents believed their child's disclosure without any doubt. A large majority of parents were rated as emotionally supportive and preoccupied by the consequence of sexual abuse (74.2\%) and took measures to protect their child from the perpetrator (84.9\%). Moreover, a large proportion of the sample (84.6\%) showed positive attitudes toward professional services for their child.

The mean for the alexithymia measure at T2 was 11.07 ( $S D=7.91$; range 0-37). Parents reported more externalizing behaviors $(M=57.89 ; S D=10.75$; range 33-85) than internalizing symptoms $(M=55.70 ; S D=11.64$; range $33-82)$. At the follow-up assessment, $26.9 \%$ of the CSA victims reached a clinical threshold for internalizing problems and $30.1 \%$ reached a clinical threshold for externalizing problems, indicated by a T-score higher than 63 . The majority of the children received psychosocial intervention for the CSA between T1 and T2 (91.6\%).

\subsection{Correlations between studied variables}

Correlations between the variables of interest were all significant (see Table 1). A lower perception of security in the relationship with both parents was associated with a higher level of alexithymia and behavior problems. A higher level of alexithymia was also associated with more internalizing and externalizing problems. Because the child's gender was not associated with any of the studied variables, it was not considered in the subsequent analysis.

\subsection{Mediation model}

A path analysis was conducted to examine the mediating role of alexithymia in the relationship between the perception of security toward both parental figures and behavior problems. All coefficients are presented in Table 2. Fig. 2 shows only significant paths of the tested model. The fit indexes were excellent, $\left(\chi^{2}(2)=3.058, p=0.217\right.$, RMSEA $=0.045$, CFI $=0.998$, and TLI $\left.=0.974\right)$. As hypothesized, alexithymia was associated with more internalizing $(b=0.52 ; p<.001)$ and externalizing $(b=0.38 ; p<.001)$ problems. However, only the perception of security toward fathers was associated with alexithymia $(b=-3.61 ; p<.05)$, which diminished the contribution of the perception of security toward mothers. Thus, an indirect effect of the perception of security toward the father on internalizing problems was obtained through alexithymia $(b=-1.89$ with $95 \%$ CI $[-3.95$ to -0.41$]$ ), with $60.9 \%$ of this effect mediated by alexithymia. An indirect effect was also observed on externalizing problems $(b=-1.38$ with $95 \%$ CI $[-3.06$ to -0.29$]$ ), with $83.3 \%$ mediated by alexithymia. The direct effect of the perception of security toward fathers on both internalizing and externalizing behaviors was not significant. The age of the child was only associated with externalizing problems $(b=-0.73$;

Table 1

Correlations among Variables.

\begin{tabular}{|c|c|c|c|c|c|c|c|}
\hline & 1 & 2 & 3 & 4 & 5 & 6 & 7 \\
\hline \multicolumn{8}{|l|}{ 1. Perception of security toward mother } \\
\hline 2. Perception of security toward father & $.29 \div * *$ & & & & & & \\
\hline 3. Alexithymia & $-.15^{*}$ & $-.23^{* *}$ & & & & & \\
\hline 4. Internalizing behavior problems $\mathrm{T} 2$ & $-.20^{* \star}$ & $-.22^{* *}$ & $.53^{\star \star * \pi}$ & & & & \\
\hline 5. Externalizing behavior problems $\mathrm{T} 2$ & $-.24 * *$ & $-.24 * *$ & $.50 \% \div *$ & $.69 \div \div$ & & & \\
\hline 6. Gender & .07 & .06 & -.14 & -.03 & -.00 & & \\
\hline 7. Psychosocial intervention & .08 & .11 & -.09 & $-.19 * *$ & $-.17^{*}$ & .12 & \\
\hline 8. Age & -.02 & -.12 & .07 & -.04 & $-.20^{* *}$ & .03 & .06 \\
\hline
\end{tabular}

Note. ${ }^{*} p<.05 .{ }^{* *} p<.01 .{ }^{* * *} p<.001$. 
Table 2

Results of the Mediation Model.

\begin{tabular}{|c|c|c|c|c|c|}
\hline Variables & $b$ & S.E. & $T$ & $p$ & $95 \%$ Boot CI \\
\hline \multicolumn{6}{|l|}{ Alexithymia } \\
\hline $\begin{array}{l}\text { Perception of security toward father } \\
\text { father }\end{array}$ & -3.61 & 1.61 & -2.25 & 0.025 & {$[-6.84,-0.67]$} \\
\hline Perception of security toward mother & -1.88 & 2.20 & -0.86 & 0.391 & {$[-5.87,2.59]$} \\
\hline \multicolumn{6}{|l|}{ Internalizing problems $\mathrm{T} 2$} \\
\hline Alexithymia & 0.52 & 0.11 & 4.75 & $<.001$ & {$[0.28,0.71]$} \\
\hline Perception of security toward father & -1.21 & 2.06 & -0.59 & 0.557 & {$[-5.26,2.73]$} \\
\hline Perception of security toward mother & -1.13 & 2.41 & -0.47 & 0.638 & {$[-5.73,3.39]$} \\
\hline Internalizing problems $\mathrm{T} 1$ & 0.43 & 0.06 & 7.58 & $<.001$ & {$[0.32,0.54]$} \\
\hline Psychosocial intervention & -8.46 & 1.75 & -4.83 & $<.001$ & {$[-12.43,-5.16]$} \\
\hline Age & -0.23 & 0.35 & -0.67 & 0.506 & {$[-0.85,0.54]$} \\
\hline \multicolumn{6}{|l|}{ Externalizing problems $\mathrm{T} 2$} \\
\hline Alexithymia & 0.38 & 0.11 & 3.64 & $<.001$ & $\begin{array}{l}{[0.16,0.58]} \\
]\end{array}$ \\
\hline Perception of security toward father & -0.28 & 1.61 & -0.17 & 0.864 & {$[-3.40,2.88]$} \\
\hline Perception of security toward mother & -2.44 & 1.65 & -1.47 & 0.140 & {$[-5.29,1.06]$} \\
\hline Externalizing problems $\mathrm{T} 1$ & 0.57 & 0.08 & 7.00 & $<.001$ & {$[0.41,0.73]$} \\
\hline Psychosocial intervention & -5.47 & 1.32 & -4.15 & $<.001$ & {$[-7.96,-2.76]$} \\
\hline Age & -0.73 & 0.34 & -2.13 & 0.033 & {$[-1.33,0.00]$} \\
\hline \multicolumn{6}{|c|}{ Conditional indirect effects with perception of security toward father } \\
\hline Internalizing problems $\mathrm{T} 2$ & -1.89 & 0.89 & -2.12 & 0.034 & {$[-3.95,-0.41]$} \\
\hline Externalizing problems $\mathrm{T} 2$ & -1.38 & 0.70 & -1.97 & 0.049 & {$[-3.06,-0.29]$} \\
\hline
\end{tabular}

Note. $\mathrm{CI}=$ Confidence interval.

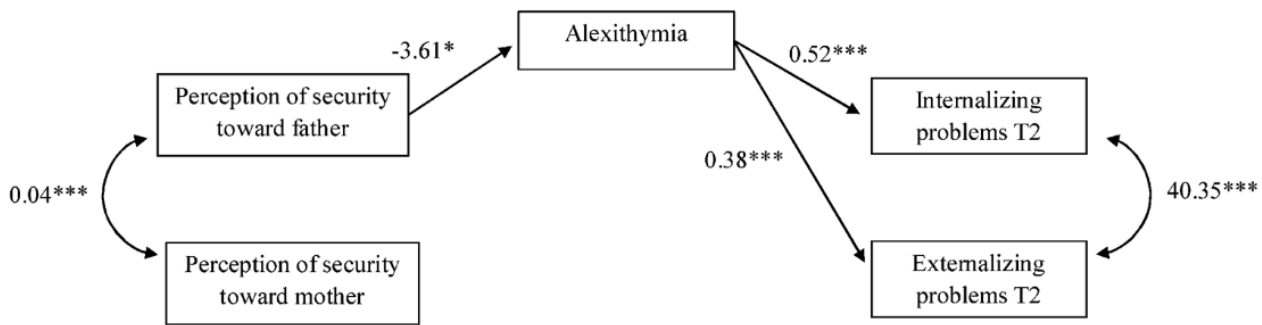

Fig. 2. Mediational Model.

Notes. The model coefficients are unstandardized. Only significant paths are presented. ${ }^{*} p<0.05 .{ }^{* *} p<0.01 .{ }^{* * *} p<0.001$. Control variables are included, but not illustrated in the model.

$p<.05)$, and psychosocial intervention was associated with both externalizing $(b=-5.47 ; p<001)$ and internalizing problems $(b$ $=-8.46 ; p<.001)$. The model explained $4.8 \%$ of the variance of alexithymia, $46.9 \%$ of internalizing problems and $56.1 \%$ of externalizing problems.

\section{Discussion}

To our knowledge, the current study is the first to investigate alexithymia among sexually abused children using a prospective design. This study aimed to ascertain the role of alexithymia in mediating the association between perceptions of security and behavior problems among sexually abused children. The results revealed that higher perceptions of security toward mothers and fathers are associated with lower levels of alexithymia as well as internalizing and externalizing problems. In addition, path analysis showed that alexithymia acted as a mediator in the relationship between perception of security toward father and both internalizing and externalizing behavior problems. These findings support the relevance of considering alexithymia among child victims of CSA and underscore the important role of fathers in sustaining children's well-being.

In accordance with past studies, bivariate analyses showed that both maternal and paternal perceptions of security were associated with internalizing and externalizing problems of sexually abused children (Parent-Boursier \& Hébert, 2015). Similarly, the mother-child and father-child relationships were associated with victims' level of alexithymia. These findings are also in line with prior studies showing that attachment security enhances children's emotional capacities (Oskis et al., 2013). Indeed, a secure parentchild relationship may act as a protective factor against the emergence of alexithymia. The presence of alexithymia is worrisome because it has deleterious effects on CSA victims' adaptation by increasing the risk of displaying behavior problems. The results are consistent with the bulk of studies showing associations between alexithymia and internalizing problems such as anxiety, depression 
and somatization (Hamaideh, 2017; Taylor \& Bagby, 2013). Interestingly, the present study shows for the first time that these findings also apply to child victims of CSA. The data also support the relevance of alexithymia to externalizing problems, although there is a paucity of literature on this topic. The current results regarding externalizing problems mirror those of Di Trani et al. (2013) obtained with a sample of preadolescents of the general population. In addition, the association between age and externalizing problems is consistent with past findings, highlighting an age decrease (Mazza et al., 2016). Clinical levels of internalizing and externalizing symptoms are similar to those found in previous studies of children victims of CSA (Parent-Boursier \& Hébert, 2014).

Our model offers more insight into the contribution of parental factors, showing that the perception of security toward the father outweighed the mother-child relationship in predicting alexithymia. In fact, a secure relationship with the father may help to buffer the deleterious effects of CSA. This finding is consistent with the results of Michiels, Grietens, Onghena, and Kuppens (2010), who posited that perceived security toward the father might have a more substantial influence than mother-child security in predicting emotional difficulties in a sample of school-aged children. However, these results are inconsistent with those of other studies. For instance, Thorberg and his colleagues' meta-analysis (2011), which included 10 studies using the Parental Bonding Instrument (Parker, Tupling, \& Brown, 1979) and the Toronto Alexithymia Scale (Bagby, Parker, \& Taylor, 1994), suggested that the maternal influence on a child's alexithymia is stronger than paternal factors in general population samples. This discrepancy between findings may be related to differences in methodology, such as reliance on adult samples or the specific measures used.

It is also possible that the father-child relationship has a greater influence on the child's ability to identify and express feelings. This influence may result from paternal figures' tendency to be more demanding conversational partners with their children than maternal figures are. Fathers tend to seek more clarification from their children, which may be beneficial for the child's emotional socialization (Dubeau \& Coutu, 2012; Le Chanu \& Marcos, 1994). Our results also point to the possibility that the father-child relationship may be particularly influential in clinical samples of children confronted with trauma. Although both caregivers are affected by the aftermath of children's disclosure of CSA, studies suggest that mothers show higher levels of psychological distress (Cyr et al., 2016). This distress may impede their availability to sustain the child's emotional expression and may lead to fathers being called upon to play a greater role in helping children express their feelings in the months following disclosure.

\subsection{Implications of the study}

The current study offers interesting insights into the importance of investigating victims' ability to identify and express feelings. Interventions targeting alexithymia could help to foster resilience and guide clinicians to target children who are at risk of acute difficulties. On the one hand, parents can support their child's emotional awareness by paying attention to the link among non-verbal clues (e.g., smile, redness), physical symptoms (e.g., stomachache, tiredness) and possible underlying feelings (Way, Yelsma, Van Meter, \& Black-Pond, 2007). These observations may be shared with the child to eventually develop the child's own capacity to be aware of his feelings and internal sensations. On the other hand, parents should be mindful of their own feelings and attitudes toward the child's emotional experience. Their sensitivity and availability may influence the child's tendency to develop and share his emotions.

Little is known about specific interventions for alexithymic individuals, especially for traumatized children (Way et al., 2007). To our knowledge, no study has explored the impact of therapy on alexithymia levels in sexually abused children. However, as suggested by the literature review of Way et al. (2007), interventions should target emotion recognition, physical sensations and strategies of emotional expression. In fact, these components are part of one of the most empirically validated interventions among CSA children: Trauma-Focused Cognitive Behavior Therapy (TF-CBT; Cohen, Mannarino, \& Deblinger, 2016). TF-CBT has been shown to efficiently reduce posttraumatic stress disorder and internalizing and externalizing problems of school-aged children who have experienced CSA (Deblinger, Mannarino, Cohen, Runyon, \& Steer, 2011). Thus, psychoeducation and the use of creative vehicles of expression to address the trauma experience (e.g., writing, drawing) may support the optimal recovery of the child following CSA disclosure. Professionals should also sensitize parents to their key role in children's capacity to identify and express feelings. The findings support the importance of soliciting both parents' presence to reduce behavioral problems in CSA victims, when possible.

\subsection{Strengths and limitations}

The present study has some limitations that need to be underlined. Considering that both alexithymia and behavior problems were evaluated by the same informant, the effect sizes of the model could have been inflated by shared-method variance. In addition, a longer delay between assessments of perceived attachment and alexithymia may offer greater insights. Despite the relevance of a child-reported measure for perceptions of security, this measure only provided a score of security or insecurity instead of categorical scores documenting different types of attachment. This limitation may have contributed to the small variance in alexithymia explained by the perception of security in the current study. Thus, future research should investigate whether different categories of insecure attachment are differently associated with alexithymia (Deborde et al., 2012). As emphasized by the meta-analysis of Brumariu et al. (2018), the use of other attachment measures may lead to different results. Investigation of the influence of differential intervention characteristics, such as the intervention format or duration, could also offer great insights.

Our study recruited children who disclosed the sexual abuse experienced and families who consulted specialized services. As such, the parents believed the children's disclosures and took the necessary steps to bring the children to the intervention center. Thus, the sampling may be biased by recruiting parents who were more supportive and sensitive to their child's needs; clinicians' reports on the PRADS suggest that our sample consisted of highly supportive parents. This kind of selection bias may tend to inflate type I error rate, as variance may be lower than in a truly randomized sample. Relatedly, the small variance in the scores for the perception of security 
toward mothers may have limited statistical power. Future research should focus on the contribution of parent-child relationships in specific aspects or dimensions of alexithymia (e.g., difficulty in identifying feelings, expressing emotions and externally oriented thinking). In fact, a subset of studies suggests that mothers and fathers may have different contributions depending on the dimension of alexithymia studied (Gil, Scheidt et al., 2008; Gil, Weigl et al., 2008). Future studies should also investigate potential variables that may impact perceived attachment security or alexithymia, such as frequency of contact or delayed disclosure. Finally, the lack of pretrauma data regarding alexithymia is an important limitation because our data do not enable us to rule out the possibility that deficits in emotion recognition existed initially. Baseline measures on alexithymia before the onset of the abuse would allow confirmation of the specific impact of CSA on alexithymia.

This study presents several strengths, such as a short-term prospective and multi-informant design, which overcomes the limitations of past studies (Taylor \& Bagby, 2013). In addition, the sample size is significant considering the population studied. The final model also allowed us to explain a large part of the variance of both internalizing and externalizing problems. In sum, the present study constitutes an important stepping-stone toward understanding the impact of parent-child relationships and emotional competencies in the trajectories of CSA victims.

\section{Acknowledgements}

This research was funded by a grant from the Canadian Institutes of Health Research (\#77614) awarded to Martine Hébert. This paper was submitted as partial recognition of the doctoral degree in psychology of the first author. She was supported by graduate scholarships from the Social Sciences and Humanities Research Council of Canada, the Faculté des Sciences humaines, the Chaire interuniversitaire Marie-Vincent sur les agressions sexuelles envers les enfants, Équipe Violence Sexuelle et Santé (ÉVISSA), Fondation de l'Université du Québec à Montréal and the Centre de recherche interdisciplinaire sur les problèmes conjugaux et les agressions sexuelles (CRIPCAS). We wish to express our gratitude to the families who participated as well as the practitioners who contributed to this research.

\section{References}

Achenbach, T. M., \& Rescorla, L. (2001). ASEBA school-age forms \& profiles: Aseba Burlington, VT.

Ainsworth, M., Blehar, S., Waters, E., \& Wall, S. (1978). Patterns of attachment: A psychological study of the strange situation. Hillsdale, NJ: Lawrence Erlbaum Associates. Bacro, F. (2011). Validation francophone de l'échelle de sécurité des perceptions d'attachement au père et à la mère (Kerns, Klepac \& Cole, 1996). Revue Européenne de Psychologie Appliquée/European Review of Applied Psychology, 61(4), 213-221. https://doi.org/10.1016/j.erap.2011.09.003.

Bagby, R. M., Parker, J. D., \& Taylor, G. J. (1994). The twenty-item Toronto Alexithymia Scale-I. Item selection and cross-validation of the factor structure. Journal of Psychosomatic Research, 38(1), 23-32. https://doi.org/10.1016/0022-3999(94)90005-1.

Barth, J., Bermetz, L., Heim, E., Trelle, S., \& Tonia, T. (2013). The current prevalence of child sexual abuse worldwide: A systematic review and meta-analysis. International Journal of Public Health, 58(3), 469-483. https://doi.org/10.1016/0022-3999(94)90005-1.

Besharat, M. A., \& Khajavi, Z. (2013). The relationship between attachment styles and alexithymia: Mediating role of defense mechanisms. Asian Journal of Psychiatry, 6(6), 571-576. https://doi.org/10.1016/j.ajp.2013.09.003.

Bhandari, S., Winter, D., Messer, D., \& Metcalfe, C. (2011). Family characteristics and long-term effects of childhood sexual abuse. The British Journal of Clinical Psychology, 50(4), 435-451. https://doi.org/10.1111/j.2044-8260.2010.02006.x.

Bolen, R. M., \& Gergely, K. B. (2015). A meta-analytic review of the relationship between nonoffending caregiver support and postdisclosure functioning in sexually abused children. Trauma, Violence \& Abuse, 16(3), 258-279. https://doi.org/10.1177/1524838014526307.

Bolen, R. M., \& Lamb, J. L. (2007). Parental support and outcome in sexually abused children. Journal of Child Sexual Abuse, 16(2), 33-54. https://doi.org/10.1300/ J070v16n02_03.

Bowlby, J. (1977). The making and breaking of affectional bonds. II. Some principles of psychotherapy. The fiftieth Maudsley Lecture. The British Journal of Psychiatry, 130(5), 421-431. https://doi.org/10.1192/bjp.130.5.421.

Bowlby, J. (1982). Attachment and loss: Retrospect and prospect. The American Journal of Orthopsychiatry, 52(4), 664. https://doi.org/10.1111/j.1939-0025.1982. tb01456.x.

Brumariu, L. E., \& Kerns, K. A. (2010). Parent-child attachment and internalizing symptoms in childhood and adolescence: A review of empirical findings and future directions. Development and Psychopathology, 22(1), 177-203.

Brumariu, L. E., Madigan, S., Giuseppone, K. R., Movahed Abtahi, M., \& Kerns, K. A. (2018). The Security Scale as a measure of attachment: Meta-analytic evidence of validity. Attachment \& Human Development, 1-26. https://doi.org/10.1080/14616734.2018.1433217.

Cassidy, J. (1994). Emotion regulation: Influences of attachment relationships. Monographs of the Society for Research in Child Development, 59(23), 228-249. https:// doi.org/10.1111/j.1540-5834.1994.tb01287.x.

Cohen, J. A., Mannarino, A. P., \& Deblinger, E. (2016). Treating trauma and traumatic grief in children and adolescents. Guilford Publications.

Craparo, G., Gori, A., Petruccelli, I., Cannella, V., \& Simonelli, C. (2014). Intimate partner violence: Relationships between alexithymia, depression, attachment styles, and coping strategies of battered women. The Journal of Sexual Medicine, 11(6), 1484-1494. https://doi.org/10.1111/jsm.12505.

Cyr, M., Frappier, J.-Y., Hébert, M., Tourigny, M., McDuff, P., \& Turcotte, M.-È. (2016). Psychological and physical health of nonoffending parents after disclosure of sexual abuse of their child. Journal of Child Sexual Abuse, 25(7), 757-776. https://doi.org/10.1080/10538712.2016.1228726.

Deblinger, E., Mannarino, A. P., Cohen, J. A., Runyon, M. K., \& Steer, R. A. (2011). Trauma-focused cognitive behavioral therapy for children: Impact of the trauma narrative and treatment length. Depression and Anxiety, 28(1), 67-75. https://doi.org/10.1002/da.20744.

Deborde, A.-S., Miljkovitch, R., Roy, C., Dugré-Le Bigre, C., Pham-Scottez, A., Speranza, M., et al. (2012). Alexithymia as a mediator between attachment and the development of borderline personality disorder in adolescence. Journal of Personality Disorders, 26(5), 676-688. https://doi.org/10.1521/pedi.2012.26.5.676.

Di Trani, M., Tomassetti, N., Capozzi, F., Solano, L., Romani, M., \& Levi, G. (2013). Alexithymia, internalizing, externalizing and obsessive-compulsive symptomatology in pre-adolescence: An empirical study on 160 subjects. Rassegna di Psicologia, 30(3), 77-94. https://doi.org/10.7379/75666.

Dubeau, D., \& Coutu, S. (2012). Le père, un acteur méconnu dans le développement social de l'enfant, Vol. 1. Presses de l’Université du Québec.

Dumont, C., \& Paquette, D. (2008). L'attachement père-enfant et l'engagement paternel: Deux concepts centraux pour mieux prédire le développement de l'enfant. Revue de Psychoéducation.

Everson, M. D., Hunter, W. M., \& Runyan, D. K. (1989). Parental reaction to abuse disclosure scale (PRADS). Chapel Hill, NC: University of North Carolina.

Frewen, P. A., Dozois, D. J., Neufeld, R. W., \& Lanius, R. A. (2008). Meta-analysis of alexithymia in posttraumatic stress disorder. Journal of Traumatic Stress, 21(2), 243-246. https://doi.org/10.1037/0021-843X.117.1.171.

Gaher, R. M., Arens, A. M., \& Shishido, H. (2015). Alexithymia as a mediator between childhood maltreatment and impulsivity. Stress and Health: Journal of the International Society for the Investigation of Stress, 31(4), 274-280. https://doi.org/10.1002/smi.2552. 
Gauthier-Duchesne, A., Hébert, M., \& Daspe, M.-È. (2017). Gender as a predictor of posttraumatic stress symptoms and externalizing behavior problems in sexually abused children. Child Abuse \& Neglect, 64, 79-88. https://doi.org/10.1016/j.chiabu.2016.12.008.

Gil, F. P., Scheidt, C. E., Hoeger, D., \& Nickel, M. (2008). Relationship between attachment style, parental bonding and alexithymia in adults with somatoform disorders. International Journal of Psychiatry in Medicine, 38(4), 437-451. https://doi.org/10.2190/PM.38.4.d.

Gil, F. P., Weigl, M., Wessels, T., Irnich, D., Baumüller, E., \& Winkelmann, A. (2008). Parental bonding and alexithymia in adults with fibromyalgia. Psychosomatics, 49(2), 115-122. https://doi.org/10.1176/appi.psy.49.2.115.

Guelzow, J. W., Cornett, P. F., \& Dougherty, T. M. (2003). Child sexual abuse victims' perception of paternal support as a significant predictor of coping style and global self-worth. Journal of Child Sexual Abuse, 11(4), 53-72. https://doi.org/10.1300/J070v11n04_04.

Hamaideh, S. H. (2017). Alexithymia among Jordanian university students: Its prevalence and correlates with depression, anxiety, stress, and demographics. Perspectives in Psychiatric Care. https://doi.org/10.1111/ppc.12234.

Harter, S. (1982). The perceived competence scale for children. Child Development, 87-97. https://doi.org/10.2307/1129640.

Hébert, M. (2001). Traduction canadienne française du Security Scale de Kerns, Klepac, \& Cole (1996). Unpublished manuscript. Université du Québec à Montréal.

Hébert, M. (2011a). Les profils et l'évaluation des enfants victimes d'agression sexuelle. L'agression sexuelle envers les enfants, 1, $149-204$.

Hébert, M. (2011). Traduction française du Children's Alexithymia Measure (CAM; Way, Applegate, Cai, Kimball, Franck, Black-Pond, Yelsma, Roberts, Hyter, \& Muliett, 2010). Unpublished manuscript. Montréal, Québec: Département de sexologie, Université du Québec Montréal.

Hébert, M., Boisjoli, C., Blais, M., \& Oussaïd, E. (2018). Alexithymia as a mediator of the relationship between child sexual abuse and psychological distress in adolescence: A short-term longitudinal study. Psychiatry Research, 260, 468-472. https://doi.org/10.1016/j.psychres.2017.12.022.

Hébert, M., Daspe, M.È., \& Cyr, M. (2017). An analysis of avoidant and approach coping as mediators of the relationship between paternal and maternal attachment security and outcomes in child victims of sexual abuse. Psychological Trauma Theory Research Practice and Policy. https://doi.org/10.1037/tra0000321.

Holodynski, M., \& Friedlmeier, W. (2006). Development of emotions and emotion regulation, Vol. 8. Springer Science \& Business Media.

Honkalampi, K., Tolmunen, T., Hintikka, J., Rissanen, M.-L., Kylmä, J., \& Laukkanen, E. (2009). The prevalence of alexithymia and its relationship with youth selfreport problem scales among finnish adolescents. Comprehensive Psychiatry, 50(3), 263-268. https://doi.org/10.1016/j.comppsych.2008.08.007.

Houck, C. D., Nugent, N. R., Lescano, C. M., Peters, A., \& Brown, L. K. (2010). Sexual abuse and sexual risk behavior: Beyond the impact of psychiatric problems. Journal of Pediatric Psychology, 35(5), 473-483. https://doi.org/10.1093/jpepsy/jsp111.

Hu, L. T., \& Bentler, P. M. (1999). Cutoff criteria for fit indexes in covariance structure analysis: Conventional criteria versus new alternatives. Structural Equation Modeling: A Multidisciplinary Journal, 6(1), 1-55.

Joukamaa, M., Taanila, A., Miettunen, J., Karvonen, J. T., Koskinen, M., \& Veijola, J. (2007). Epidemiology of alexithymia among adolescents. Journal of Psychosomatic Research, 63(4), 373-376. https://doi.org/10.1016/j.jpsychores.2007.01.018.

Keefer, K. V., Taylor, G. J., Parker, J. D., \& Bagby, R. M. (2017). Taxometric analysis of the Toronto structured interview for alexithymia: Further evidence that alexithymia is a dimensional construct. Assessment, 1-11. https://doi.org/10.1177/1073191117698220.

Kerns, A. K., \& Brumariu, L. E. (2016). Attachment in middle childhood. In J. Cassidy, \& P. R. Shaver (Eds.). Handbook of attachment: Theory, research, and clinical applications (pp. 295-316). (3rd ed.). New York, NY, US: Guilford Press.

Kerns, K. A., Klepac, L., \& Cole, A. (1996). Peer relationships and preadolescents' perceptions of security in the child-mother relationship. Developmental Psychology, 32(3), 457. https://doi.org/10.1037/0012-1649.32.3.457.

Kim, J., \& Cicchetti, D. (2004). A longitudinal study of child maltreatment, mother-child relationship quality and maladjustment: The role of self-esteem and social competence. Journal of Abnormal Child Psychology, 32(4), 341-354.

Kim, J., \& Cicchetti, D. (2010). Longitudinal pathways linking child maltreatment, emotion regulation, peer relations, and psychopathology. Journal of Child Psychology and Psychiatry, 51(6), 706-716. https://doi.org/10.1111/j.1469-7610.2009.02202.x.

Krystal, J. (1988). Assessing alexithymia. Integration and Self-Healing, 286-310.

Langevin, R., Cossette, L., \& Hébert, M. (2016). Emotion regulation in sexually abused preschoolers. Child Psychiatry and Human Development, 47(1), 1-12. https://doi. org/10.1007/s10578-015-0538-y.

Le Chanu, M., \& Marcos, H. (1994). Father-child and mother-child speech: A perspective on parental roles. European Journal of Psychology of Education, 9(1), 3-13. https://doi.org/10.1007/BF03172881.

Lecours, S., Philippe, F. L., Boucher, M.-È., Ahoundova, L., \& Allard-Chapais, C. (2016). Negative self-evaluating emotions as mediator in the relationship between childhood emotional trauma and alexithymia in adulthood. Journal of the American Psychoanalytic Association, 64(5), 1027-1033. https://doi.org/10.1177/ 0003065116675876.

Lemche, E., Klann-Delius, G., Koch, R., \& Joraschky, P. (2004). Mentalizing language development in a longitudinal attachment sample: Implications for alexithymia. Psychotherapy and Psychosomatics, 73(6), 366-374. https://doi.org/10.1159/000080390.

Lemelin, J.-P., \& Tarabulsy, G. M. (2012). Développement social et émotionnel chez l'enfant et l'adolescent: Les bases du développement, Vol. 1. Presses de l'Université du Québec.

Levant, R. F., Hall, R. J., Williams, C. M., \& Hasan, N. T. (2009). Gender differences in alexithymia. Psychology of Men \& Masculinity. https://doi.org/10.1037/ a0015652.

Madigan, S., Brumariu, L. E., Villani, V., Atkinson, L., \& Lyons-Ruth, K. (2016). Representational and questionnaire measures of attachment: A meta-analysis of relations to child internalizing and externalizing problems. Psychological Bulletin, 142(4), 367. https://doi.org/10.1037/bul0000029.

Marriott, C., Hamilton-Giachritsis, C., \& Harrop, C. (2014). Factors promoting resilience following childhood sexual abuse: A structured, narrative review of the literature. Child Abuse Review, 23(1), 17-34. https://doi.org/10.1002/car.2258.

Mattila, A. K., Kronholm, E., Jula, A., Salminen, J. K., Koivisto, A.-M., Mielonen, R.-L., et al. (2008). Alexithymia and somatization in general population. Psychosomatic Medicine, 70(6), 716-722 doi: 0.1016/j.paid.2010.03.038.

Mattila, A. K., Keefer, K. V., Taylor, G. J., Joukamaa, M., Jula, A., Parker, J. D., et al. (2010). Taxometric analysis of alexithymia in a general population sample from Finland. Personality and Individual Differences, 49(3), 216-221. https://doi.org/10.1016/j.paid.2010.03.038.

Mazza, J. R. S., Boivin, M., Tremblay, R. E., Michel, G., Salla, J., Lambert, J., et al. (2016). Poverty and behavior problems trajectories from 1.5 to 8 years of age: Is the gap widening between poor and non-poor children? Social Psychiatry and Psychiatric Epidemiology, 51(8), 1083-1092. https://doi.org/10.1007/s00127-016$1252-1$.

Michiels, D., Grietens, H., Onghena, P., \& Kuppens, S. (2010). Perceptions of maternal and paternal attachment security in middle childhood: Links with positive parental affection and psychosocial adjustment. Early Child Development and Care, 180(1-2), 211-225. https://doi.org/10.1080/03004430903415064.

Muthén, L. K., \& Muthén, B. O. (1998-2007). Mplus user's guide (sixth edition). Los Angeles (CA): Muthén \& Muthén.

Nemiah, J. C., \& Sifneos, P. E. (1970). Psychosomatic illness: A problem in communication. Psychotherapy and Psychosomatics, 18(1-6), 154-160. https://doi.org/10. $1159 / 000286074$.

Orejuela-Dávila, A. I., Cann, A., \& Tedeschi, R. G. (2017). Alexithymia predicts posttraumatic growth and distress after trauma. Journal of Loss \& Trauma, 22(3), 171-182. https://doi.org/10.1080/15325024.2017.1284468.

Oskis, A., Clow, A., Hucklebridge, F., Bifulco, A., Jacobs, C., \& Loveday, C. (2013). Understanding alexithymia in female adolescents: The role of attachment style. Personality and Individual Differences, 54(1), 97-102. https://doi.org/10.1016/j.paid.2012.08.023.

Paquette, D. (2004). La relation père-enfant et l'ouverture au monde. Enfance, 56(2), 205-225. https://doi.org/10.3917/enf.562.0205.

Parent, N., \& Hébert, M. (2006). Questionnaire sur la victimisation de l'enfant. Adaptation du History of Victimization Form par Wolfe, Gentile \& Boudreau (1987). Montréal, Canada. Département de sexologie, Université du Québec à Montréal.

Parent-Boursier, C., \& Hébert, M. (2010). La perception de la relation père-enfant et l'adaptation des enfants suite au dévoilement d'une agression sexuelle. Canadian Journal of Behavioural Science/Revue canadienne des sciences du comportement, 42(3), 168. https://doi.org/10.1037/a0017691.

Parent-Boursier, C., \& Hébert, M. (2014). L'influence de la relation au père et à la mère sur les troubles de comportement des enfants victimes d'agression sexuelle: une étude de suivi. International Journal of Victimology/ Journal International de Victimologie, 12(1), 26-39. 
Parent-Boursier, C., \& Hébert, M. (2015). Security in father-child relationship and behavior problems in sexually abused children. Journal of Family Violence, 30(1), 113-122. https://doi.org/10.1007/s10896-014-9653-y.

Parker, G., Tupling, H., \& Brown, L. (1979). A parental bonding instrument. Psychology and Psychotherapy Theory Research and Practice, 52(1), 1-10. https://doi.org/10. 1111/j.2044-8341.1979.tb02487.x.

Parker, J. D., Eastabrook, J. M., Keefer, K. V., \& Wood, L. M. (2010). Can alexithymia be assessed in adolescents? Psychometric properties of the 20-item Toronto Alexithymia Scale in younger, middle, and older adolescents. Psychological Assessment, 22(4), 798. https://doi.org/10.1037/a0020256.

Parker, J. D., Keefer, K. V., Taylor, G. J., \& Bagby, R. M. (2008). Latent structure of the alexithymia construct: A taxometric investigation. Psychological Assessment, 20(4), 385. https://doi.org/10.1037/a0014262.

Rieffe, C., \& De Rooij, M. (2012). The longitudinal relationship between emotion awareness and internalising symptoms during late childhood. European Child \& Adolescent Psychiatry, 21(6), 349-356. https://doi.org/10.1007/s00787-012-0267-8.

Säkkinen, P., Kaltiala-Heino, R., Ranta, K., Haataja, R., \& Joukamaa, M. (2007). Psychometric properties of the 20-item Toronto Alexithymia Scale and prevalence of alexithymia in a Finnish adolescent population. Psychosomatics, 48(2), 154-161 doi: 10.117/appi.psy.48.2.

Sawyer, G. K., \& Hansen, D. J. (2014). Heterogeneous symptom patterns of sexually abused children in treatment: Understanding the complexity of the problem. Journal of Child Sexual Abuse, 23(8), 900-917. https://doi.org/10.1080/10538712.2014.964439.

Schimmenti, A., Passanisi, A., Caretti, V., La Marca, L., Granieri, A., Iacolino, C., et al. (2017). Traumatic experiences, alexithymia, and Internet addiction symptoms among late adolescents: A moderated mediation analysis. Addictive Behaviors, 64, 314-320. https://doi.org/10.1016/j.addbeh.2015.11.002.

Sedlak, A. J., Mettenburg, J., Basena, M., Peta, I., McPherson, K., \& Greene, A. (2010). Fourth national incidence study of child abuse and neglect (NIS-4). Washington, DC: US Department of Health and Human Services Retrieved on July, 9, 2010.

Sifneos, P. E. (1973). The prevalence of 'alexithymic'characteristics in psychosomatic patients. Psychotherapy and Psychosomatics, 22(2-6), 255-262. https://doi.org/ $10.1159 / 000286529$.

Spaccarelli, S. (1994). Stress, appraisal, and coping in child sexual abuse: A theoretical and empirical review. Psychological Bulletin, 116(2), 340. https://doi.org/10. 1037/0033-2909.116.2.340.

Taylor, G. J., \& Bagby, R. M. (2013). Psychoanalysis and empirical research: The example of alexithymia. Journal of the American Psychoanalytic Association, 61(1), 99-133. https://doi.org/10.1177/0003065112474066.

Thériault, C., Cyr, M., \& Wright, J. (1995). Traduction et Adaptation du Parental Reaction to Abuse Disclosure Scale de Everson et al. (1989) [Translation of Parental Reaction to Abuse Disclosure Scale]. Unpublished manuscriptUniversité de Montréal.

Thériault, C., Cyr, M., \& Wright, J. (2003). Facteurs contextuels associés aux symptômes d'adolescentes victimes d'agression sexuelle intrafamiliale. Child Abuse \& Neglect, 27(11), 1291-1309. https://doi.org/10.1016/j.chiabu.2003.04.001.

Thomas, R., DiLillo, D., Walsh, K., \& Polusny, M. A. (2011). Pathways from child sexual abuse to adult depression: The role of parental socialization of emotions and alexithymia. Psychology of Violence, 1(2), 121. https://doi.org/10.1037/a0022469.

Thompson, R. A. (2013). Socialization of emotion and emotion regulation in the familiy. In J. J. Gross (Ed.). Handbook of emotion regulation (pp. 173-186). (2nd ed.). New York, NY: The Guilford Press.

Thorberg, F. A., Young, R. M., Sullivan, K. A., \& Lyvers, M. (2011). Parental bonding and alexithymia: A meta-analysis. European Psychiatry, 26(3), 187-193. https:// doi.org/10.1016/j.eurpsy.2010.09.010.

Vachon, D. D., Krueger, R. F., Rogosch, F. A., \& Cicchetti, D. (2015). Assessment of the harmful psychiatric and behavioral effects of different forms of child maltreatment. JAMA Psychiatry, 72(11), 1135-1142. https://doi.org/10.1001/jamapsychiatry.2015.1792.

Velotti, P., Garofalo, C., Petrocchi, C., Cavallo, F., Popolo, R., \& Dimaggio, G. (2016). Alexithymia, emotion dysregulation, impulsivity and aggression: A multiple mediation model. Psychiatry Research, 237, 296-303. https://doi.org/10.1016/j.psychres.2016.01.025.

Venta, A., Mellick, W., Schatte, D., \& Sharp, C. (2014). Preliminary evidence that thoughts of thwarted belongingness mediate the relations between level of attachment insecurity and depression and suicide-related thoughts in inpatient adolescents. Journal of Social and Clinical Psychology, 33(5), 428-447. https://doi. org/10.1521/jscp.2014.33.5.428.

Way, I. F., Applegate, B., Cai, X., Franck, L. K., Black-Pond, C., Yelsma, P., et al. (2010). Children's Alexithymia Measure (CAM): A new instrument for screening difficulties with emotional expression. Journal of Child \& Adolescent Trauma, 3(4), 303-318. https://doi.org/10.1080/19361521.2010.523778.

Way, I., Yelsma, P., Van Meter, A. M., \& Black-Pond, C. (2007). Understanding alexithymia and language skills in children: Implications for assessment and intervention. Language, Speech, and Hearing Services in Schools, 38(2), 128-139. https://doi.org/10.1044/0161-1461(2007/013).

Yancey, C. T., \& Hansen, D. J. (2010). Relationship of personal, familial, and abuse-specific factors with outcome following childhood sexual abuse. Aggression and Violent Behavior, 15(6), 410-421. https://doi.org/10.1016/j.avb.2010.07.003.

Zimmermann, G., Quartier, V., Bernard, M., Salamin, V., \& Maggiori, C. (2007). The 20-item Toronto Alexithymia Scale: Structural validity, internal consistency and prevalence of alexithymia in a swiss adolescent sample. L'Encéphale, 33(6), 941-946. https://doi.org/10.1016/j.encep.2006.12.006. 